\title{
Diagrams and algorithms
}

(C) The Author(s)

10.2218/finsoc.v2i2.1729

\section{Paolo Cirio}

Conceptual artist, USA

\section{I.}

With economic structures, I investigate and propose economic models that challenge the creation of monetary value and its distribution. Through the creation of economic systems I focus on creative possibilities to address both the misuses and opportunities of financial instruments. This critique comprises ephemeral structures of complex materials that I assemble and perform to unveil and manipulate the flow of power dynamics among individuals, society, governments, and corporations.

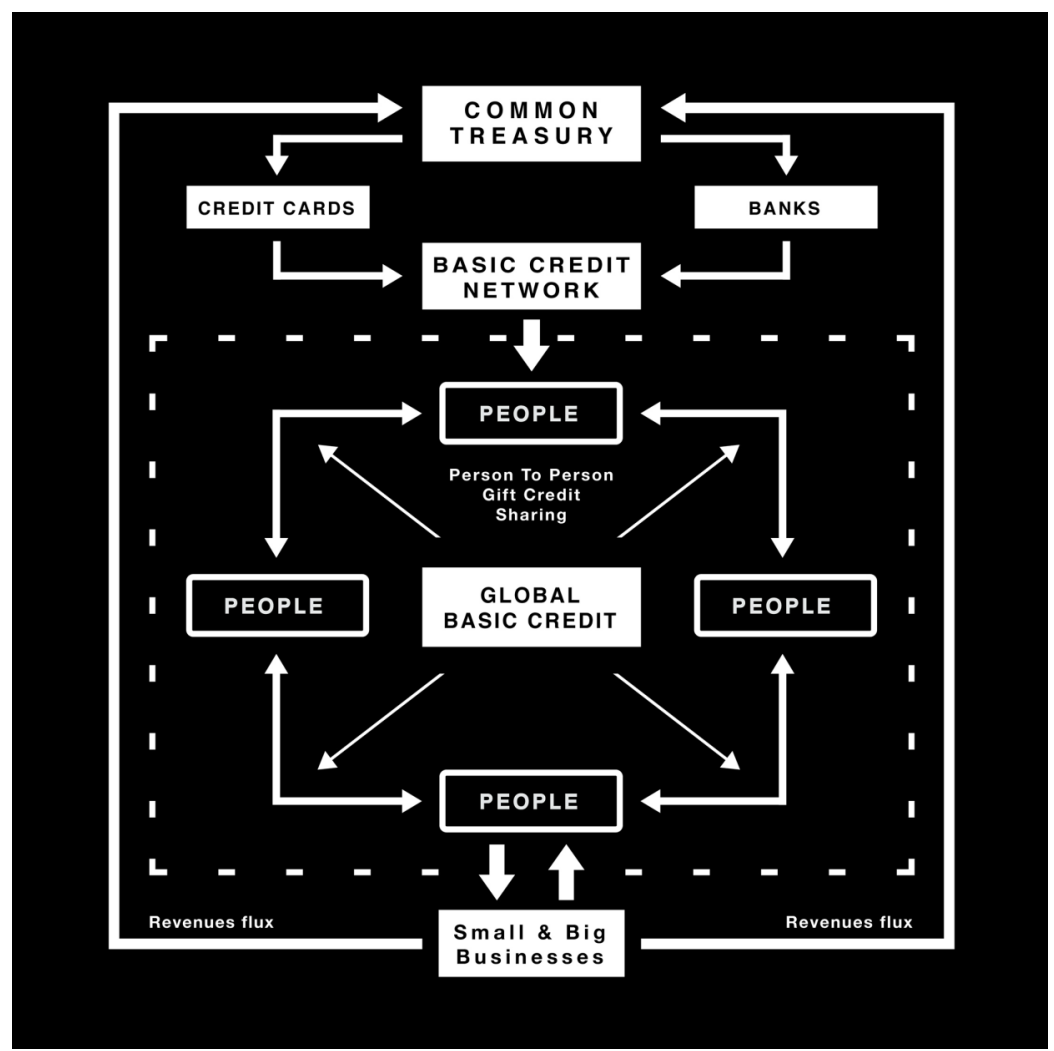

Figure 1. Paolo Cirio, P2P Gift Credit Card - Gift Finance, 2010. Digital print and plastic card embossed. https://paolocirio.net/work/p2p-gift-credit-card/ 
II.

In my artworks I explore the creative process of rearranging the attributes of those flows and structures, a practice that eventually affects the agents involved in these social contracts and transactions directly. As such, my work is meant to be an active social agent that generates responses and inspiration, serving as a catalyst for reflection and change among the social actors that constitute the formation of society.

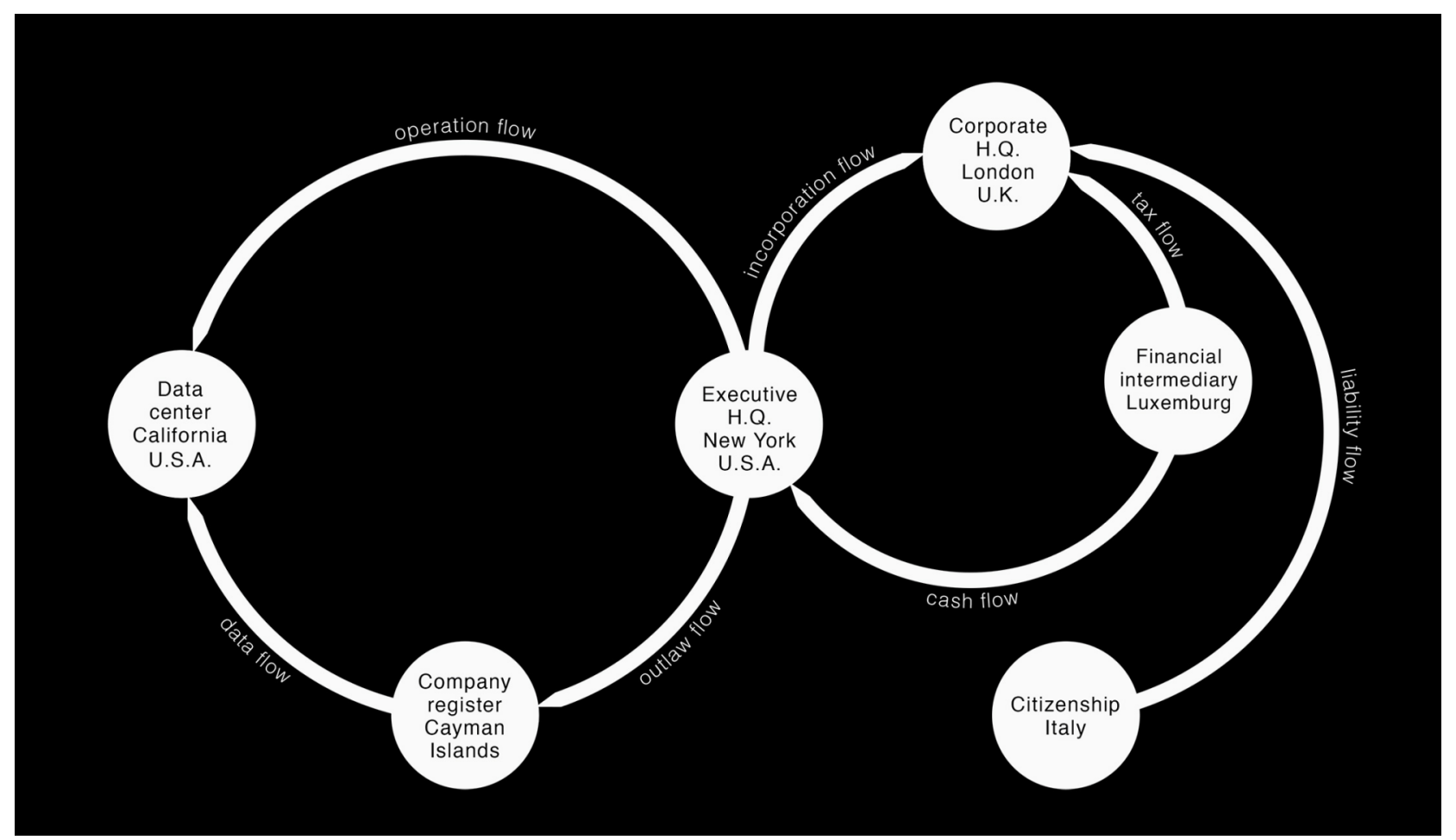

Figure 2. Paolo Cirio, Loophole for All, 2013. Digital prints US letter size, two video channels. https://paolocirio.net/work/loophole-for-all/ 
III.

Reformulations of contemporary socio-economic conditions and conflicts become my actual work. Finance is a complex structure that creates social conflict globally, which can potentially be steered aesthetically.
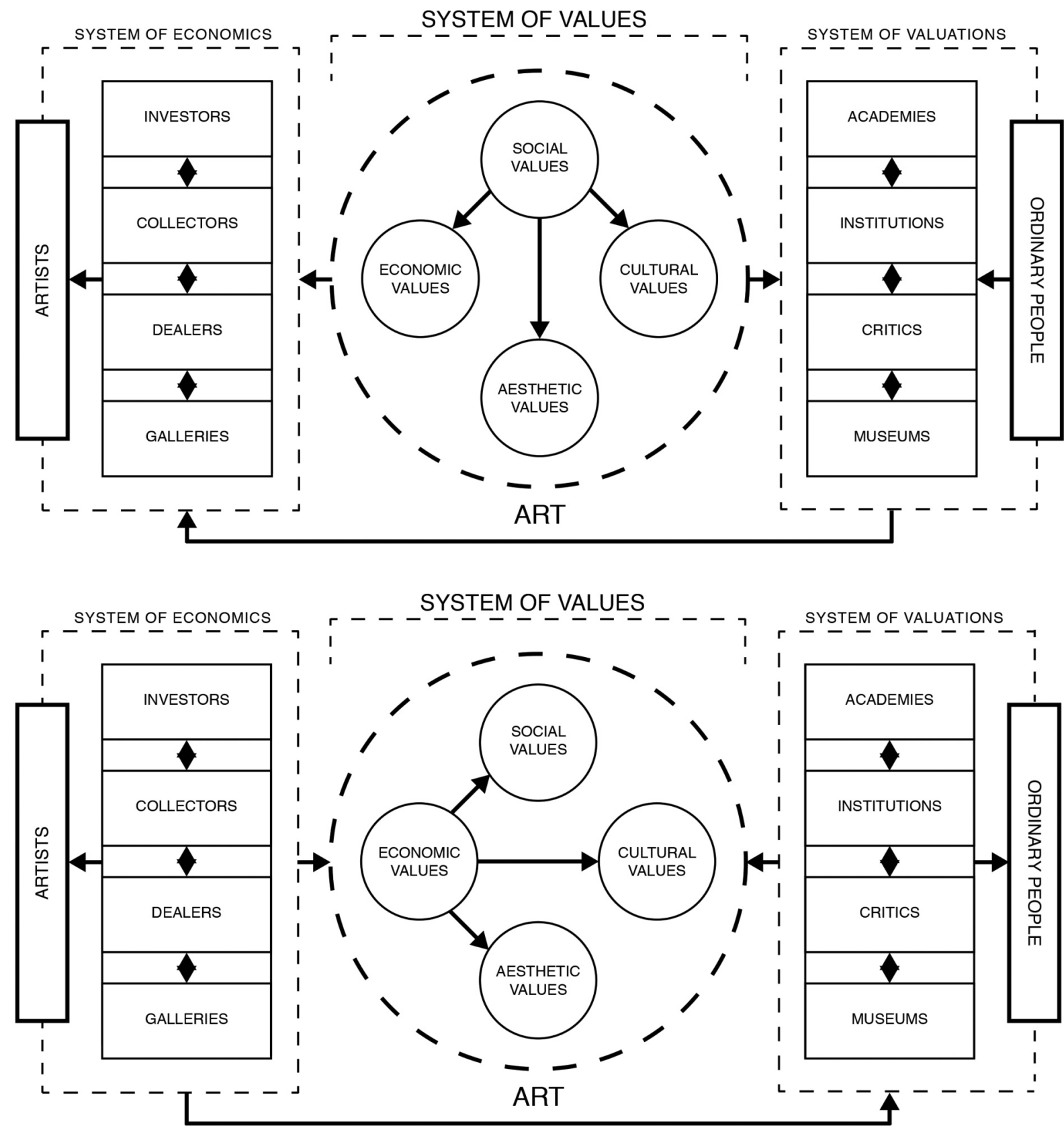

Figure 3. Paolo Cirio, Art Commodities, 2014. Digital prints. https://paolocirio.net/work/artcommodities 


\section{IV.}

I draw algorithms to illustrate how I created a process of intervention in the structures and how the flow of information and its dynamic has been reorganized to execute the artworks or to allude to a potential social reality that can be made possible by considering the algorithm on a large scale, therefore referring to new modes of social performances and conceptualism.

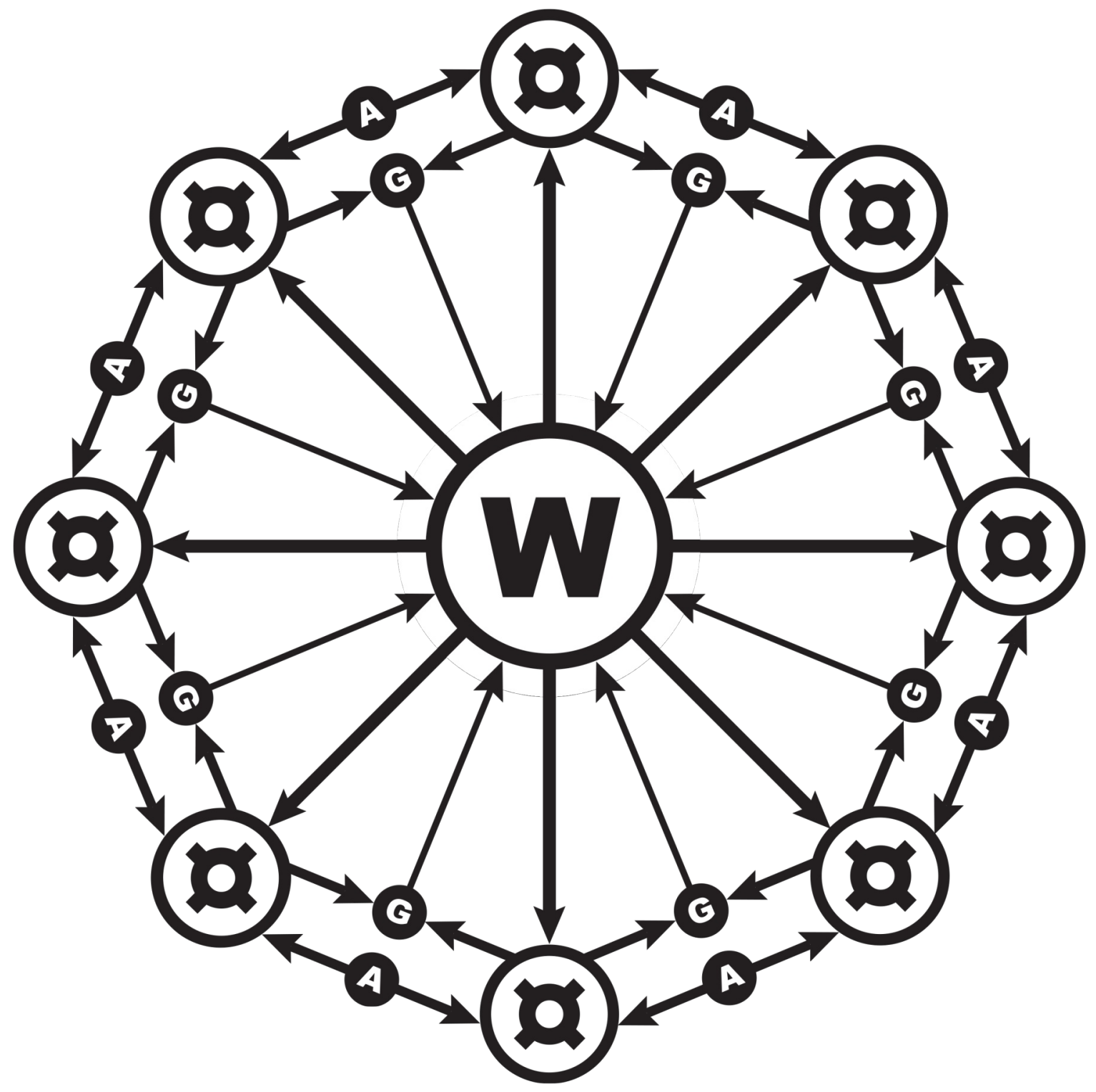

Figure 4. Paolo Cirio, (W)orld Currency Equation, 2014. Digital prints. https://paolocirio.net/work/world-currency/

Legend

W: Value of World Currency. Symbol (W)

a: Any currency symbol in the basket

A: Average of exchange rates between each pair of currencies in the basket

G: Average of spreads between each pair of currencies in the basket over time 
Paolo Cirio is a conceptual artist who works with legal, economic and semiotic systems of the information society. He investigates social fields impacted by the Internet, such as privacy, copyright, politics and finance. He shows his research and intervention-based works through artifacts, photos, installations, videos, and public art. Cirio has exhibited in international museums and institutions and has won a number of awards, including Golden Nica at Ars Electronica, Transmediale Prize and the Eyebeam fellowship, among others. Visit his website at https://paolocirio.net/ 